\title{
Spatially bounded regions for resource governance
}

\section{Reeve and D. Brunckhorst*}

$\mathrm{D}$ espite a growing body of theory that emphasises the importance of socio-spatial aspects in the representation of community interests, regionalisation for natural resource governance remains dominated by river catchments. At the same time, Australian local governments are being given increasing responsibilities for environmental and resource management, but work within boundaries that are largely historical artefacts. The confluence of these trends suggests it is timely to examine the requirements for spatial definition of resource governance regions. We contend that there are three essential requirements for efficient and effective natural resource planning and governance. First, the nature and reach of environmental externalities of resource use should determine the size and nesting of resource management regions. Second, the boundaries of resource governance regions should enclose areas of greatest interest and importance to local residents. Third, the biophysical characteristics of a resource governance region should be as homogenous as possible. We applied these principles to the derivation of an 'eco-civic', resource governance regionalisation for New South Wales. This article describes the concepts needed for this work, the results and their potential policy application. An important finding was that many regionalisations in use in New South Wales fall short on a regionalisation performance measure developed to gauge the fragmentation of representation of community interests.

\section{Introduction}

Negative externalities lie at the heart of most natural resource and environmental management issues. They occur when the actions of one resource user pursuing their own private interests have a detrimental impact upon other resource users or the public more generally. Resource governance is the process of collective

\footnotetext{
* Ian Reeve and David Brunckhorst are with Institute for Rural Futures and UNESCO Centre for Bioregional Resource Management, University of New England, Armidale, NSW. Email:dbrunckh@une.edu.au
}

decision-making by which the actions of those with interests in natural resources are constrained and coordinated to ensure sustainable use of resources and equitable access by private and public users.

While there are many ways by which societies resolve and coordinate the competing demands of resource users, ranging from unfettered markets to sovereign decree, it is representative democracy that forms the foundation for resource governance in Australia. In addition, resource governance leans more towards Rousseau's vision of representative democracy with citizen participation in collective decision-making than Schumpeter's representative democracy where decision-making is left to professional elites and the legislatures (James and Blamey 1999).

The quantity and complexity of externalities that must be resolved by resource governance is constantly increasing for at least two reasons. Firstly, as noted as long ago as 1961 by Peacock and Wiseman, population growth leads to increasing interdependence between citizens and an increasing potential for externalities from private consumption and production decisions. Secondly, the impacts of modern technology and the overloaded assimilative capacity of ecosystems results in the constant emergence of new externality problems that span distances from the local to the global (Reeve 1997; Reeve et al. 2002a).

With the resulting complex of socio-economic and ecological interdependencies operating at various scales (e.g. Slocombe 1993; Brown and MacLeod 1996; Berkes and Folke 1998), the task of deciding who will be represented or will participate in what level of collective decision-making is a formidable one. Local resource issues need a local forum and regional issues need a regional forum, but where should the boundaries be drawn to define the constituencies for each forum? Resource management decisions made without adequate representation of stakeholder interests are likely to be ignored or actively resisted.

The frequency with which resource governance arrangements are re-organised in Australia, and the ongoing public policy debates over access to natural resources suggests that resource governance is not working well. Similar misgivings are expressed in other countries (Johnson et al. 1999; Barham 2001; Carpenter and Gunderson 2001; Blomquist and Schlager 2005). 
The geographical focus in this article is the State of New South Wales, although the discussion and findings are applicable elsewhere in Australia and overseas. In short, we contend that the placement of boundaries to define local and regional constituencies for natural resource governance warrants more careful analysis than it has been accorded in the past. In particular, there is a growing body of literature on the social dimensions of regionalisation for resource governance and public administration that has important implications for the two main resource management regionalisations in use in Australia - catchments and local government areas. After introducing this literature, and describing the origins of catchment-based and local government regionalisations in New South Wales, we propose three principles to be followed in defining spatial boundaries for resource governance regions. We then demonstrate an empirical method for deriving a nested hierarchy of such regions, consistent with these principles.

\section{Regionalisations with a social dimension}

During the $1990 \mathrm{~s}$, academic interest in public participation in natural resource governance has increased markedly (see review by Buchy et al. 2000), while theories of 'place' and 'community' have gained increasing empirical support and refined definitions in recent years (Feld and Basso 1996; Wilkinson 2000; Stedman 2003; Cheng et al. 2003; Parisi et al. 2004).

In her review of 'Community of Interest' concepts, Fulcher (1989, p. 4) suggested three critical dimensions of community of interest (see also Walmsley 1977):

- perceptual (sense of belonging)

- functional (common activities)

- political (representation of interests).

There has also been increasing understanding of the role 'place' and 'community' play in influencing natural resource politics and management (Beckley 1995; Brandenburg and Carroll 1995; Shannon 1998; Parisi et al. 2004; Carr 2004). Indeed, an examination of the underlying theories of landscape ecology and demography by Field et al. (2003) highlighted the need to refine techniques to represent the spatial aspects of social relationships so that landscape patterns and processes might be better understood.

One such technique, based on the concept of 'social catchments' has been operationalised and refined by Graeme Hugo and Peter Smailes at the University of Adelaide since the 1970s (Hugo et al. 2001). In recent years, two other groups in Australia have started working in this area: Mark Fenton at James Cook University in Townsville, and the authors of this article at the University of New England in Armidale. A review of these concepts and techniques was undertaken by Colin Macgregor at the Australian Bureau of Rural Sciences. The publication of this work (Hugo et al. 2001, p. 49) defined social catchments as:

The territory occupied by a group of households and individuals who are in some form of regular interaction and which the inhabitants identify as 'their' community or region.

Social catchments, so defined, are almost invariably centred on one or more urban areas or central places. The concept owes much to central place theory (Christaller 1933) and gravity modelling (Carrothers 1956), particularly with respect to the idea that social catchments may form nested hierarchies. However, in operationalising the concept, the three groups in Australia have taken distinctly different directions (Hugo et al. 2001).

The method used by the University of Adelaide group (e.g. Smailes 1999) involves mail surveys of people living outside urban centres. These surveys gather information about the spatial extent of the community with which people identify, their attitudes about this community, and the normal place of purchase of selected goods and services. This information is used to identify the 'rural neighbourhoods' recognised by respondents, and larger 'rural communities' which show the areas over which respondents travel to make purchases.

The Town Resource Cluster method developed by Fenton et al. (2000) is based on the calculation of dependency measures between towns. These measures are derived from interviews and secondary data relating to business expenditure, employee expenditure, employee residential locations, social infrastructure services, and facilities and social networks. This enables groups of towns with high inter-dependency to be identified (Hugo et al. 2001). The method has been applied to regional economies based on particular natural resources, such as fisheries, water resources or timber.

By the time the review by Hugo et al. (2001) was completed, the authors of this article had developed the forerunner of the technique described in this article (Brunckhorst 2000, 2002; Brunckhorst and Coop 2001).

\section{'Regions' for resource governance}

The dominant regionalisations for instrumentalities with resource management powers in Australia at the present time are based on river catchments and local government areas. 


\section{River catchments}

River catchments have become the dominant form of regionalisation for natural resource governance in many countries. Modern integrated catchment management has its roots in early twentieth century progressivism in the United States (Waldo 1984; Margerum 1995; Muskingum Water Conservancy District 2002). In the 1960s, new social movements concerned with environmental and civil rights issues led to increased demands for direct citizen participation in public policy making. Along with many other areas of public policy, integrated catchment management responded with a shift from technocratic planning to various forms of participative planning. In Australia, this shift took place in the late 1980s and early 1990s, with little consideration either of the implications for the definition of resource governance regions, or of the considerable body of relevant theory in the social sciences that existed at that time. The latter included central place theory (Christaller 1933), gravity modelling (Carrothers 1956), theories of community and place attachment (Kemmis 1990; Altman and Low 1992; Cuba and Hummon 1993) and hierarchy theory in natural resources management (Pattee 1973; Urban et al. 1987).

Catchments are now the dominant administrative unit for regional natural resource governance in Australia and elsewhere (Reeve et al. 2002a, 2002b; Phelps 2003). Within the integrated catchment management literature, most authors accept unquestioningly that catchments should form the areal units within which natural resource governance takes place. Others (e.g. McGinnis et al. 1999; Webler and Tuler 1999) make a case that smaller river catchments can sometimes form a natural unit encompassing cultural and social commonalities.

However, there is a growing weight of argument against the assumption that catchment-based regions or local government areas automatically incorporate all resource governance issues and their communities of interest (Omernik and Bailey 1997; Getches 1998; Blomquist and Schlager 2005; O'Neill 2005). Brunckhorst (2000, 2002), Parisi et al. (2003, 2004) and Johnson et al. (1999) have also pointed out that regions of similar biophysical attributes and climate have little correlation to either watershed topography or areas of interest to land use communities. Barham (2001) argued that processes of democratic deliberation that have evolved over long periods of time prior to the emergence of modern environmentalism cannot necessarily be fitted to catchment boundaries.

In Australia, several authors have argued that the boundaries of communities, that might form natural units within which resource governance issues are negotiated and resolved, rarely coincide with physical catchment boundaries (Brunckhorst 2000; Ewing 2003; Lane et al. 2004; O'Neill 2005). Syme et al. (1994) went so far as to suggest that organisation of community involvement on catchment boundaries acts against the achievement of the stated goals and purposes of integrated catchment management.

\section{Local government}

Local government in New South Wales had its origins in central Sydney in the early nineteenth century. The Municipalities Act 1858 made it possible for any town, city, hamlet or rural district to be proclaimed a municipality if a petition was signed by a group of at least fifty ratepayers. A Local Government Areas Commission was constituted in January 1905 to create local government areas (shires) within the unincorporated areas of New South Wales, with the exception of the Western Division. The Commission was required, inter alia, to pay due consideration to community and diversity of interest, lines of communication, physical features, and the necessary expenditure of any proposed shire for bridges, roads, and works of public utility (Maiden 1966; Musgrave et al. 1985).

Throughout the twentieth century, the great technological and economic changes, and increasing responsibility for environmental management through changes in public policy, have brought pressure for structural reform in local government (NSW Department of Local Government 2004). The rationale for structural reform, however, has often only focused on the potential for financial 'efficiencies' from joining existing local government areas (Dollery and Johnson 2005).

Episodes of local government amalgamation and boundary change have continued in New South Wales, and other states, to the present day. The question of the location of boundaries however, has received very little attention other than in the context of debates about amalgamation of adjoining local government areas, based on existing boundaries (see, for example, NSW Department of Local Government 2004). One exception was Walmsley (1977) who highlighted some of the issues surrounding identity with communities of interest and apparently disparate shire boundaries.

At the same time as structural reform in local government has largely ignored the question of boundary location outside of existing boundaries, local government finds itself with increasing environmental and natural resource management responsibilities (House of Representatives 
Standing Committee on Economics, Finance and Public Administration 2003). Many of these responsibilities, such as drawing up and regularly reviewing local environment plans, and becoming the regulatory authority for premises licensed under various state Acts dealing with water pollution and contaminated land, are specifically concerned with the management of environmental externalities.

\section{Regionalisation principles for resource governance}

Despite the issues raised in the two previous sections, there have been surprisingly few attempts to propose and apply empirical techniques of regionalisation that might address some of these issues and build on the growing body of theory about the socio-spatial aspects of natural resource governance (see Omernik and Bailey 1997; Brunckhorst 2000).

An exception, and the subject of this article, is the major study (2003-2004) by the Institute for Rural Futures to derive a nested hierarchy of resource governance regions for the rural part of the State of New South Wales in Australia (Brunckhorst et al. 2004). For this study, it was necessary to distil from the growing literature on sociospatial aspects of natural resource governance some principles that could inform the detailed methodological development. The three principles that were chosen are now described.

\section{Principle 1: The nature and reach of the environmental externalities of resource use determine the size and nesting of resource governance regions}

The need for collective decision making about natural resource use derives from the fact that one person's use of natural resources impacts upon other people. The spatial extent of these environmental externalities can range from the local (e.g. noise pollution), to the regional (e.g. groundwater extraction from regional aquifers), to the national or global (e.g. carbon dioxide emissions). If those who create, and those who are affected by these externalities, are to be represented in collective decision making, then the resource governance region within which this takes place has to be of a similar scale as the reach of the externalities (see McGinnis 1999; Cole 2002).

Many environmental externalities operate simultaneously across a range of scales. For example, vegetation clearing for agriculture on a farm might result in outbreaks of salinised land on adjacent farms, and an increase in salinity of surface waters which impacts on urban water users 1000 kilometres downstream. For this reason, it is likely that in most areas resource governance regions will need to be nested, with smaller regions (dealing with local problems) nested within larger regions (dealing with environmental externalities with a longer reach). The principles by which nested resource governance regions might operate are beyond the scope of this article (see McGinnis 1999; Reeve 2003; Marshall 2005). However, it can be noted that such cross-scale nesting of institutions and landscapes is generally regarded as providing efficiencies in administration, monitoring and governance (Berkes and Folke 1998; McGinnis 1999; Marshall 2005).

\section{Principle 2: The boundaries of natural resource governance regions should pass through areas of minimum collective interest to local people}

People are quite capable of identifying the locality of their 'place attachment', or the area they regard as their community (Hillery 1955; Kemmis 1990; Altman and Low 1992; Cuba and Hummon 1993; Brandenburg and Carroll 1995; Wilkinson 2000; Hobbs et al. 2002; Cheng et al. 2003; Stedman 2003). Previous studies (Brunckhorst and Coop 2001; Coop 2003; Brunckhorst et al. 2006) demonstrated that there is a high degree of spatial conformity between the areas regarded as the location of one's community, the areas regarded as acceptable for the residential location of one's elected representative in local government, the area of one's local social networks and interactions, and the areas within which one would wish to be consulted about resource governance decisions affecting those areas. Such an area is referred to here as a 'community area'. While people will have interests in distant places too, their local community area is the locus of substantial social and economic interaction with other residents, and of interaction with the natural resource base.

Almost any point in the landscape will lie within one or more community areas belonging to the people living in the vicinity of that point. A point in the landscape that lies within a large number of overlapping community areas is a point in which a correspondingly large number of people have an interest. Resource governance decisions affecting this point in the landscape will have to consider the interests of this large number of people. If the boundaries of natural resource governance regions cut through such an area, thereby also cutting through the community areas of a large number of people, local community participation and engagement will be greatly compromised. Indeed, it is likely that many residents will feel dissatisfied with consultative processes and the representation of their interests (Knight and Landres 
1998; Shannon 1998; Reeve et al. 2002a, 2002b; Parisi et al. 2003, 2004).

Other points in the landscape will lie within relatively few community areas. If the boundaries of natural resource governance regions pass through these parts of the landscape, then a minimum of people will be in a situation in which their community area is divided between one or more resource governance regions. For this reason, the second principle proposes that resource governance boundaries should pass through points that lie within relatively few community areas.

Principle 3: For effective and efficient natural resource governance, it is important that the administrative region within which management occurs contains a relatively homogeneous set of landscapes - climate, ecological characteristics and resources

The biosphere can be divided into continents and oceans, and further subdivided into broad continental regions. These can be subdivided into ecoregions and landscapes, and landscapes into ecosystem components, and further subdivided into patches or structural units and so on (Wiken 1986; Omernik 1987, 1995; Bailey 1996; Brunckhorst 2000). Across broad continental regions, patterns are generally observable at various spatial scales where similar organisms or biophysical attributes occur together. These mosaics are composed of units within which internal homogeneity is relatively high. When similar recurring ecological communities are replaced by a different set of recurring natural units, landscape boundaries can be observed and their underlying causes inferred fairly accurately (Forman and Godron 1981; Hansen and di Castri 1992; Forman 1995). Considerable gains in efficiency can be made if planning, priority setting, and resource governance actions take account of these boundaries (Reid and Murphy 1995; Johnson et al. 1999; McGinnis et al. 1999; Brunckhorst 2000; Field et al. 2003).

\section{Empirical derivation of resource governance regions}

The method developed in this study consisted of three major components:

- derivation of a hierarchy of biophysical regions (to satisfy principles one and three)

- derivation of a hierarchy of 'civic' regions such that the boundaries pass through the community areas of relatively few people (to satisfy principle two)

- optimisation of the boundaries of the two hierarchical regionalisations so that all three principles are satisfied to the maximum degree possible.
The following sections describe the methods followed and results for each of these three components, with an emphasis on the social surface and civic regions.

\section{Biophysical regionalisation}

The biophysical regionalisation was based on elevation, soil moisture, soils, and climate data at scales of one kilometre or finer, using the ERDAS Imagine 8.5 classification routine (for details, see Brunckhorst et al. 2004). The result was a hierarchical biophysical regionalisation comprising eight major regions (level one), each of which was divided into sub-regions (level two). The level two sub-regions were further subdivided into two or more level three sub-regions. By virtue of the classification routine, the regions or sub-regions at each level have relatively homogenous biophysical characteristics, thereby meeting the requirements of principle three. Because negative externalities are generally transmitted between resource users by hydrological or ecological processes, the biophysical homogeneity of the regions and sub-regions means that similar externality issues will occur in these regions. The externalities with a short geographical reach will be entirely contained within a level three sub-region, while amalgamation of level three sub-regions into level two sub-regions or level one regions will be necessary to encompass externalities with a longer geographical reach. In this way, the requirements of principle one are met. The biophysical regionalisation is shown in Figure 1.

\section{Social surface and civic regionalisation}

The methods currently being used in Australia for the derivation of social catchments are highly dependent on the acquisition of primary data from surveys of residents and, for economic reasons, are infeasible to apply on a large scale (Smailes 1987; Hugo et al. 2001; Coop 2003; Brunckhorst et al. 2006).

A modelling approach was developed that could use mostly secondary data, and which utilised insights from theories of place and cognitive mapping (e.g. Hillery 1955; Tuan 1974; Altman and Low 1992; Cuba and Hummon 1993; Austin 1994; Kearney and Kaplan 1997; Hobbs et al. 2002; Cheng et al. 2003). This modelling approach was based on the findings from primary data gathered in earlier work by the authors in northern New South Wales. This showed that the community areas that people drew on a map of their region approximated ellipses in outline, with sizes ranging from a few kilometres across the shortest dimension to over a hundred kilometres (Brunckhorst and Coop 2001; Coop 2003; Brunckhorst et al. 2006). For the majority of rural residents, the ellipse was defined by their place of 


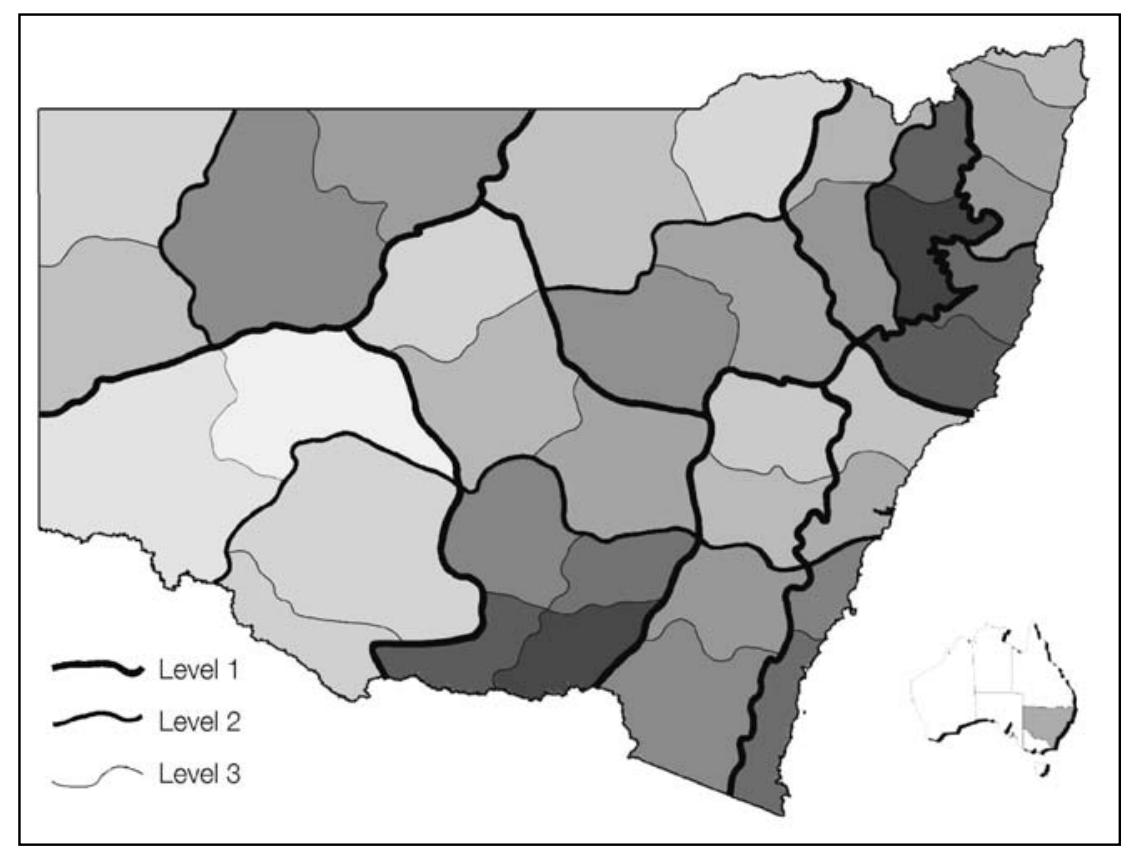

Figure 1 Boundaries of the hierarchical biophysical regionalisation of the State of New South Wales

residence (home point) at one end of the ellipse and a town at the other end (Figure 2). For residents in smaller towns or villages, the elliptical community area generally included the nearest larger town, while for residents in larger towns, the community area included one or more smaller towns in the region, usually along major highways. Community areas tended to be larger in the more sparsely settled regions of northern New South Wales, and smaller in the more densely settled coastal regions. This suggested that it would be possible to model community areas by populating the State of New South Wales with simulated home points (i.e. places of residence), and attaching an elliptical simulated community area to each home point, appropriately sized and orientated according to the location of towns of various sizes in the vicinity (Brunckhorst et al. 2004).

\section{Simulating home points}

A spatial resolution of one kilometre had been set for the study which led to a spacing of simulated home points at intervals of 500 metre or less. The census collection districts (CCDs) for New South Wales were ranked by population density, and the population fraction for simulation for the least dense CCD set to a value that would provide for distances of 500 metres between simulated home points when that fraction of the population of the CCD was uniformly distributed across the geographical extent of the CCD. The required population fraction for the least dense CCD was found to be 0.66 (i.e. if two thirds of the population of the CCD were spread uniformly across the CCD, then the simulated home points would be 500 metres apart). However, if this value was to be used in densely settled areas, this would result in far more simulated home points than needed to generate the social surface described below. Accordingly, a continuously variable population fraction was used, where the fraction was an inverse function of population density. This resulted in one simulated home point per CCD in metropolitan areas and large cities. The procedure described above resulted in 14 339 simulated home points spread across New South Wales.

\section{Simulating community areas}

Simulated elliptical community areas were derived using the equation for an ellipse from analytical geometry with

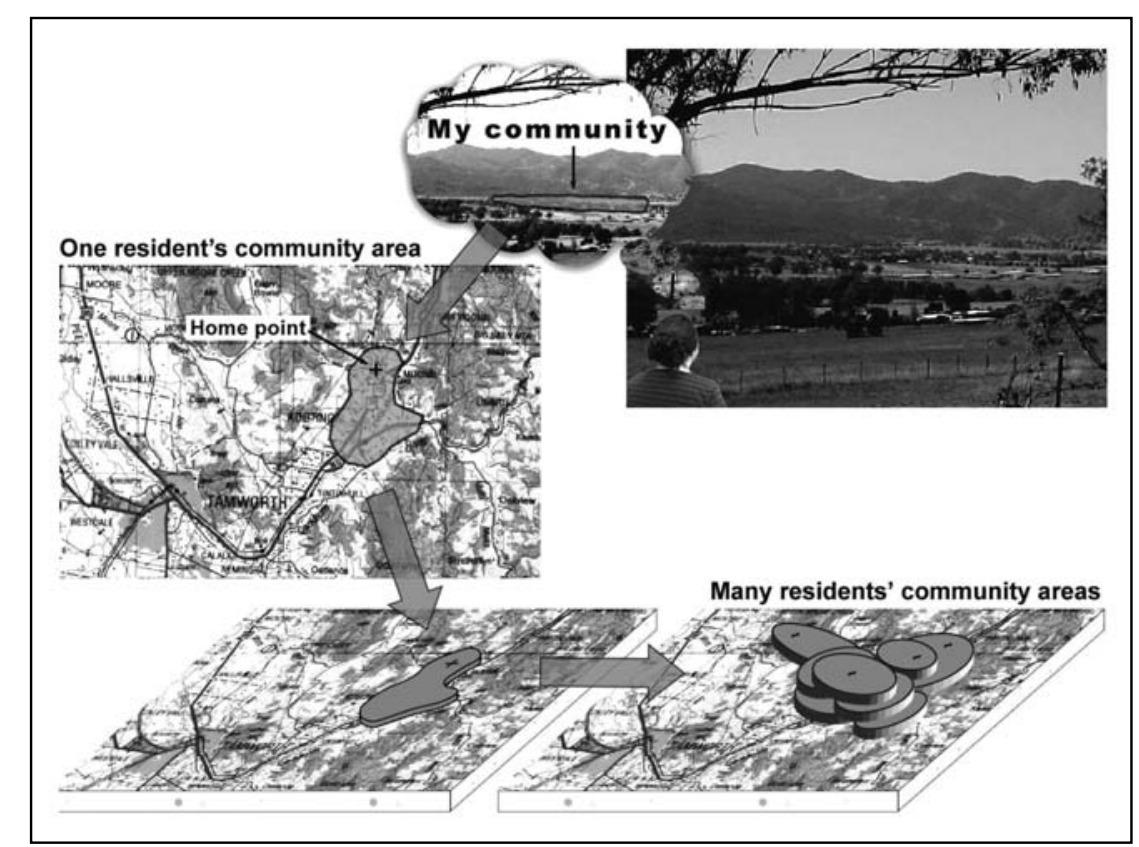

Figure 2 A resident's community area of interest and close social networks can be mapped. When many residents' community areas are mapped, they stack up into a 'social surface' having a characteristic topography 


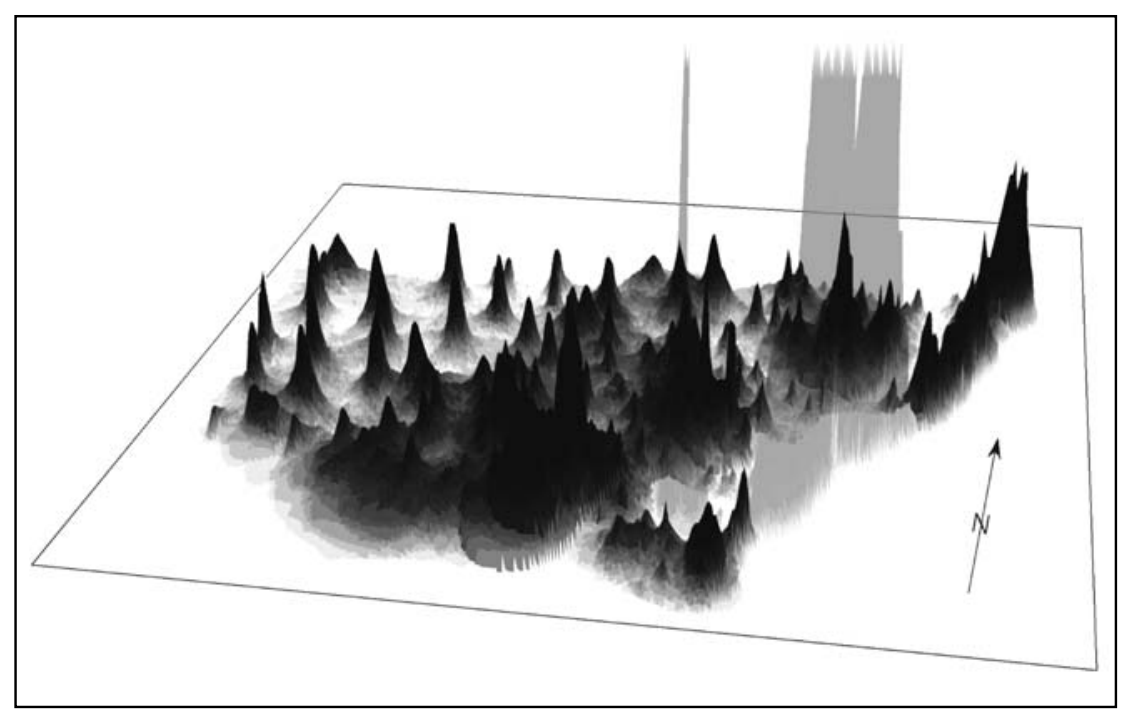

Figure 3 Simulated social surface for New South Wales (With the exception of the Sydney and Canberra regions, darker areas indicate higher elevations of the surface. The peaks in the surface representing Sydney and Canberra have been truncated and rendered semi-transparent to avoid obscuring the parts of the surface behind these peaks.)

various parameters to adjust its size and orientation. Simulated community areas, sized and oriented according to the factors mentioned in the previous section were placed on each of the simulated home points. The different sizes of community areas in different parts of New South Wales were simulated by dividing the state into five regions, each region having a different mean community area size. These mean sizes were chosen to reflect the variation in community area size known from the earlier northern New South Wales study (Coop 2003; Brunckhorst et al. 2004, 2006). As community areas were generated by the model in each region, they were randomly varied in size to give a size distribution similar in shape to that found in the northern New South Wales primary data, with a mean community area size equal to that set for the region.

The second transformation of the simulated community areas was to orientate them such that they included one or more towns in the vicinity of the home point. To avoid boundary effects in regions close to the New South Wales border, towns in Queensland, South Australia and Victoria were included among the towns influencing the orientation of generated community areas.

The final step in the modelling procedure was to assign each simulated community area a height of one unit in a third dimension at right angles to the north-south and east-west dimensions of the map of New South Wales. Working in this three-dimensional space, the simulated community areas were summed to produce a 'social surface'. High points on this surface corresponded to points that lay within the community areas of relatively large numbers of people (strictly, large numbers of simulated home points). Low points on the surface corresponded to points that lay within the community areas of relatively few people. As proposed in principle two, above, it is these low points in the social surface that are suitable areas through which resource governance region boundaries might pass. The social surface obtained by summing the elliptical community areas on each of the 14339 simulated home points is shown in oblique view in Figure 3.

\section{Deriving a hierarchy of civic regions}

To produce a hierarchy of regions based on the simulated social surface it is necessary to locate major and minor 'valleys' in the surface. Boundaries based on the major valleys will define larger level one regions, and boundaries following the valleys within these regions will define the smaller level two sub-regions. Once again, boundaries on minor valleys within the level two subregions will define the yet smaller level three subregions.

The hydrological modelling tool in ESRI ArcView 3.2 was used to produce a 'drainage network' on the modelled social surface. Valleys at the lower 'altitudes' of the modelled social surface, indicate possible locations for level one boundaries, those in the middle altitudes level two boundaries and those at the upper altitudes level three boundaries. In some areas, the 'topography' of the social surface did not necessarily give a strong indication as to the placement of boundaries. This was a consequence of broad shallow valleys in the surface, or the presence of several valleys in close proximity that were equally good candidates for the location of a boundary. For this reason, a telephone survey of a number of community organisations with hierarchical structures of local, regional and state branches was undertaken. Use of key informants is an efficient way of gathering surrogate data or for 'ground-truthing' (Cheng et al. 2003; Parisi et al. 2003). Smailes (1987) and Tonts and Atherley (2005) have demonstrated the important role that sport plays in the structure of rural communities and regions, and the spatial expansion of interacting (or amalgamated) sporting organisations. A total of 403 interviews with office bearers in the Country Women's Association, the Hockey Association, the Soccer 


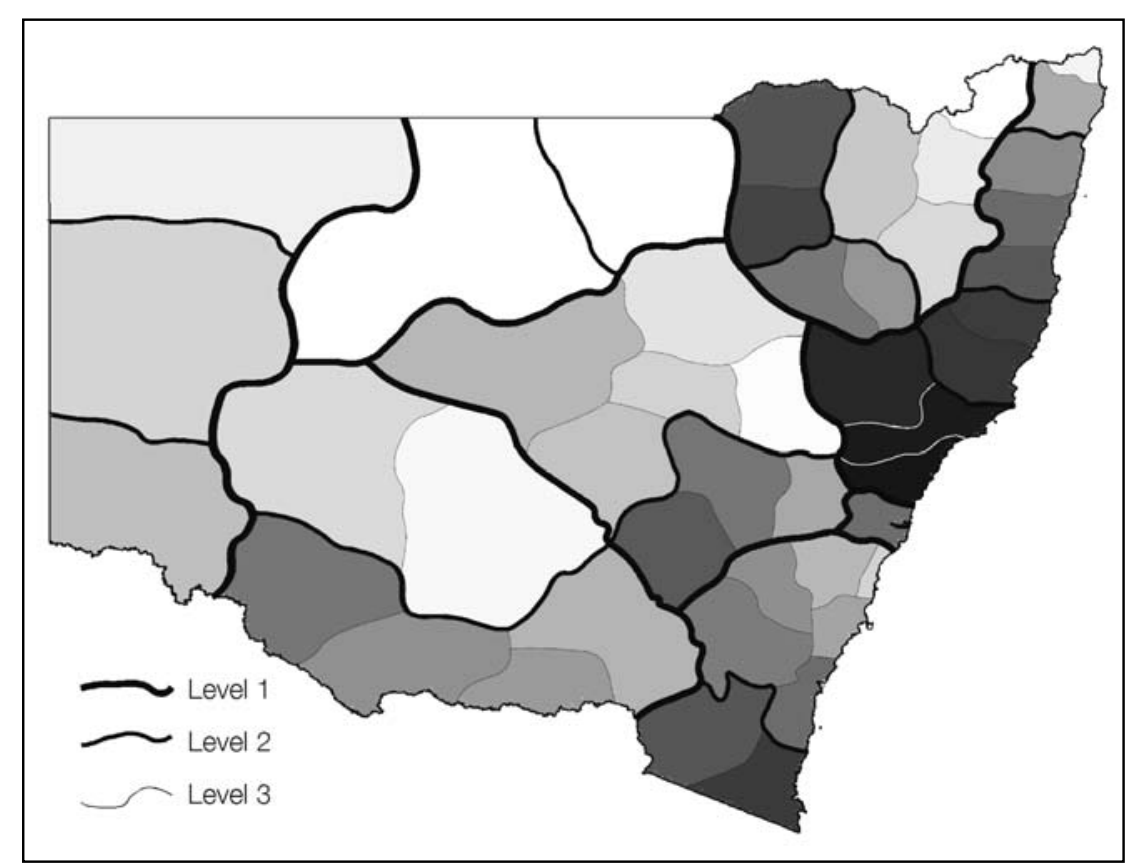

Figure 4 Hierarchy of civic regions derived from the simulated social surface of the 1973 home points in the region for which measured data was available (Kappa=0.982, $\mathrm{p}<0.0005)$.

\section{Eco-civic optimisation}

The boundaries that define the biophysical regionalisation in Figure 1, being derived to satisfy principles one and three, do not necessarily coincide with the boundaries of the civic regionalisation in Figure 4, where the boundaries were derived to satisfy principle two, although the coincidence is fairly good along the eastern escarpment of the northern tablelands. This is because a sparsely settled area coincides with a major climatic, floral and faunal discontinuity in the landscape.

In many areas it is necessary to adjust the boundaries of the civic regions to bring them into closer coincidence with the boundaries of the biophysical

Association and the Netball Association were completed. Interviewees were asked about the localities in their region where their organisation interacted with similar organisations as part of social activities and/or sporting competitions. Information from the telephone survey of community organisations and the 'drainage network' was combined to produce a three-level hierarchical regionalisation of the modelled social surface - the hierarchy of civic regions shown in Figure 4.

\section{Validation of the hierarchy of civic regions}

The earlier study by Coop (2003) derived an empirically measured social surface and associated set of civic regions for northeastern New South Wales, against which the modelled civic regions could be compared using the Kappa statistic (Carletta 1996). A classification matrix was used to record, for each civic region, the proportion of home points that were assigned to the same civic region when the modelled surface is used to derive the boundaries between the regions (Brunckhorst et al. 2004, 2006). The level of agreement (Carletta 1996) between the modelled boundaries and the measured boundaries in north-eastern New South Wales was extremely good, with correct classifications of more than 98.6 per cent

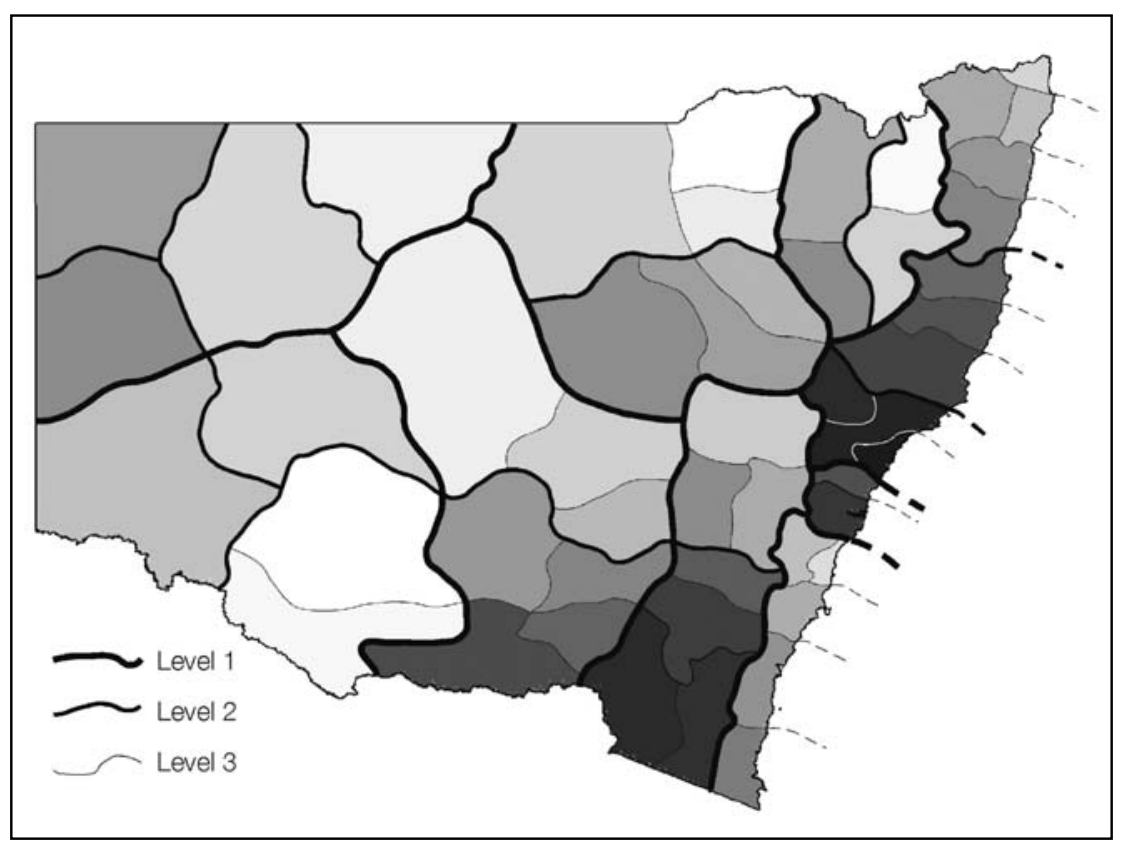

Figure 5 Hierarchy of eco-civic regions for New South Wales, following optimisation of the boundaries of the biophysical and civic regionalisations 


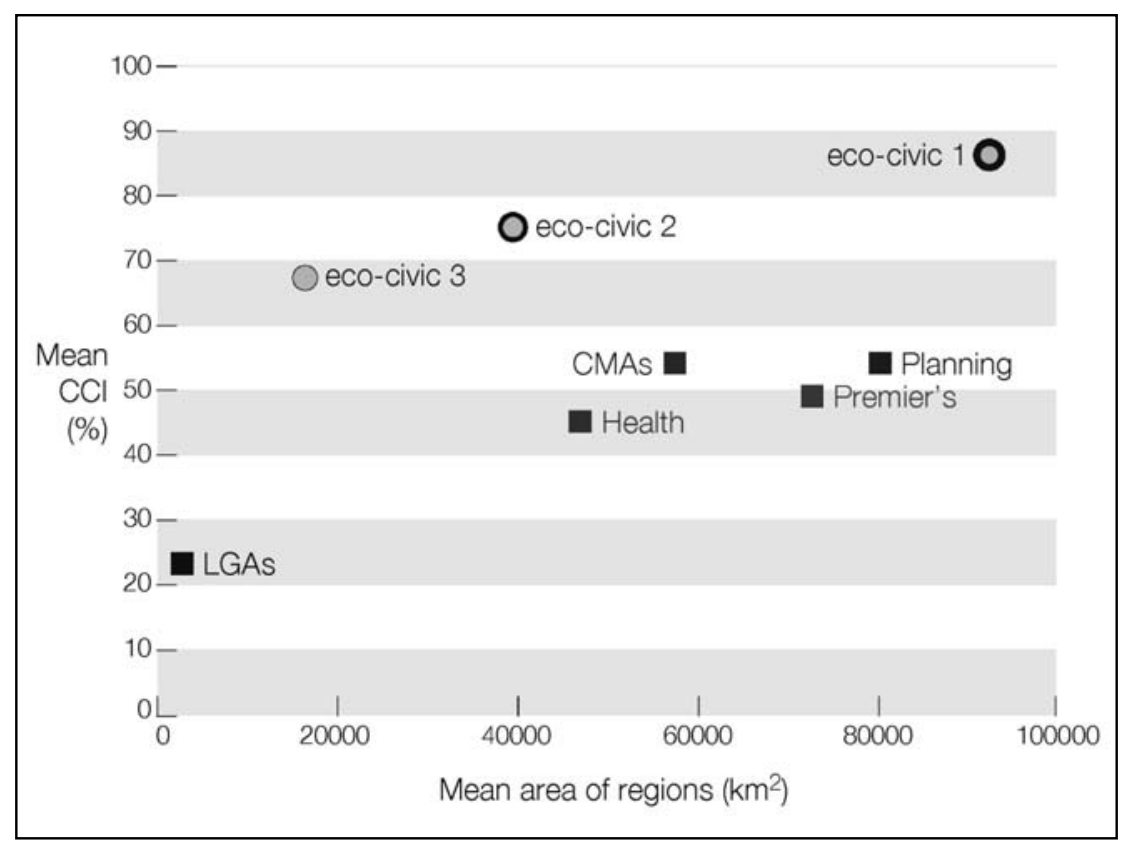

Figure 6 Mean Community Capture Index (CCI) plotted against mean area of regions for a range of administrative regions in New South Wales. (LGAs = local government areas; Health = NSW Department of Health; CMAs = NSW Catchment Management Authority; Premier's = NSW Premier's Department; Planning = NSW Department of Planning)

2004, 2006). At broader scales therefore (i.e. level one), the optimisation routine can give more weight to the biophysical boundaries. However, at finer scales (i.e. level three) it is necessary to ensure that the optimisation routine does not shift boundaries into relatively high areas on the social surface. The process of optimising boundaries to take account of the above considerations is termed 'ecocivic optimisation', and the resulting set of regions is termed an 'eco-civic regionalisation' (Brunckhorst et al. 2004). The eco-civic regionalisation for New South Wales is shown in Figure 5. For this study, eco-civic optimisation was carried out manually by visual inspection and comparison of the biophysical regionalisation and the valleys in the social surface, although with sufficient time and resources, it would be possible to develop an algorithm to provide a mathematical optimisation of the boundaries.

\section{Comparing the performance of regionalisations}

For any given administrative region, some community areas will be wholly within the region boundary, while others will be intersected by the region boundary. The proportion of people's community areas that are wholly within a region boundary, compared to the total number of people living within that boundary, provides an index of the performance of the particular resource governance region in terms of its ability to include the areas that are of interest to residents.

This index is termed the 'Community Capture Index' (CCI). The CCI provides a means of comparing the performance of different regionalisations in terms of the extent to which people's community areas are intersected by region boundaries (Brunckhorst et al. 2004, 2006). In conformity with principle two, above, a regionalisation with boundaries that intersect fewer community areas (higher value of the CCI), is preferable to a regionalisation that intersects a greater number of community areas (lower value of the CCI). A value of 100 per cent means that all community areas are contained within the region. A value of 20 per cent means that only one fifth of community areas are contained within the region, and the remaining four fifths are intersected in some way by the region boundary.

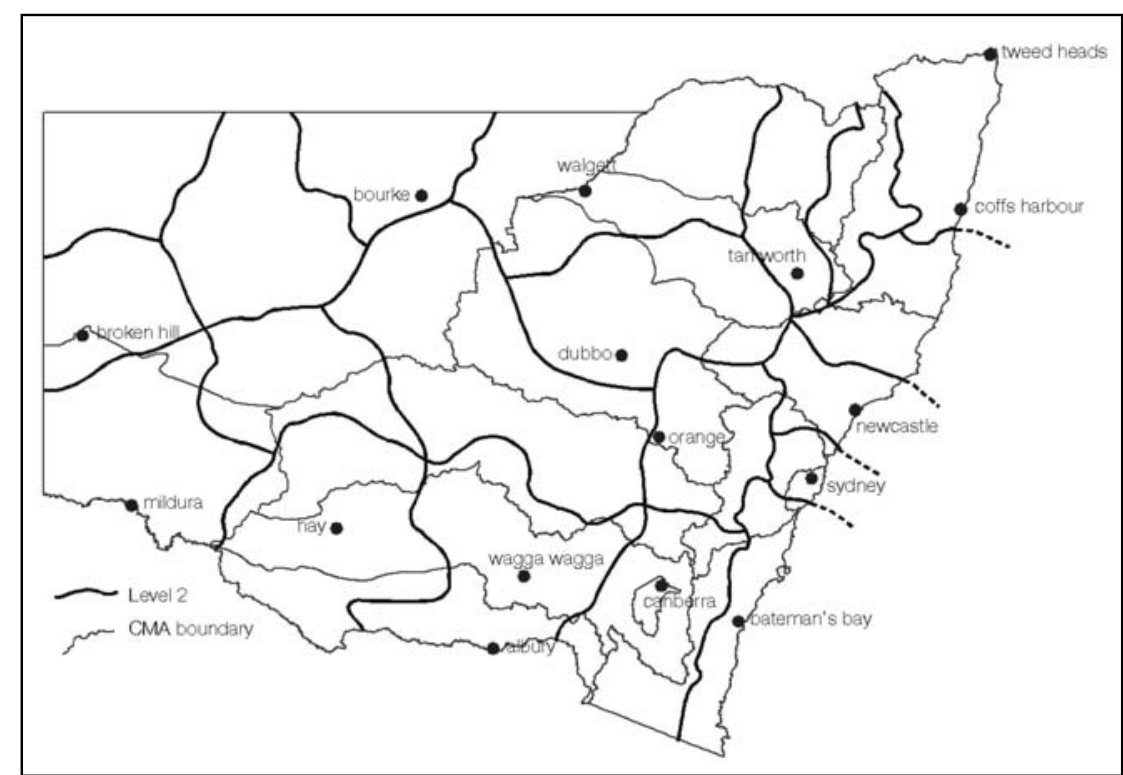

Figure 7 Boundaries of catchment management authorities and the level two eco-civic regionalisation showing lack of representation of area of interest to land use communities and ecological variables 
The CCI can be calculated for any given region, such as a local government area or a catchment management authority (CMA), using GIS software. The count of the number of community areas whose boundaries do not intersect the boundary of the region of interest is divided by the count of the total number home points within the region.

Figure 6 plots the CCIs for the three levels of the ecocivic regionalisation, and for a range of current administrative regions in New South Wales, including the New South Wales CMA regions, the latter being based on catchment boundaries. The figure demonstrates that the current administrative boundaries and those of the CMAs are not in the best locations if the intersection of people's community areas by these boundaries is to be minimised (Figure 6). If the boundaries of the CMAs are overlaid on the boundaries of the level two eco-civic regions (Figure 7), it can be seen that these catchmentbased boundaries are a poor fit with both the areas of community interest and with ecoregions.

\section{Conclusions}

The emergence of catchments and watersheds in the last three decades as the dominant method to delineate regions for resource governance has assumed that rainfall, temperatures, soils, vegetation, other biodiversity, land use, and ground water, along with community engagement and collective action best occur within such regions. At the same time, local government is taking on an increasing range of natural resource governance functions, working within jurisdictional boundaries that are largely historical artefacts.

This article proposes three principles to underpin the development of regionalisations for natural resource governance - including both the administration and community representation functions of governance. These principles require that resource governance regions reflect the scale of the environmental externalities, are biophysically homogeneous and have boundaries that pass through areas of minimum community interest. While some small watersheds and sub-catchments might possess these characteristics, most do not.

The study is not concerned with economic efficiencies in local government or catchment organisations. Rather, we have argued that the central function of catchment management organisations, and a growing function of local government is the resolution of negative externality conflicts among public and private resource users. The efficient performance of this function requires jurisdictional boundaries that meet the three principles proposed in this article.

However, the adjustment of jurisdictional boundaries is by no means costless, and the costs of dysfunctional resource governance will need to be substantial before adjustment of boundaries should be considered. If, in the future, the point is reached when the costs of the adjustment of boundaries are outweighed by the gains in effective resource governance, then the methods described in this article will be of utility. The balance point at which adjustment of boundaries and responsibilities becomes feasible may not be far off in some regions of Australia where environmental externalities are severe and resource policy highly contested, as the current negotiation of state and federal responsibilities in the Murray-Darling Basin demonstrates.

The study has established a practical method to achieve a hierarchical regionalisation that satisfies the proposed regionalisation principles. The method is based on established theory, a small amount of primary data, readily available secondary data, and some primary validation work. As such, it is more cost-effective than methods based on extensive primary data collection.

The study has also proposed an index (the Community Capture Index) that provides a numerical measure of the extent to which boundaries might divide areas of the landscape with which people identify and in which they have an interest. Application of the Index to administrative regionalisation currently in use, such as local government boundaries and catchment boundaries, demonstrates that the majority of boundaries (including amalgamated local government areas retaining previous boundaries) do not reflect the scale of externalities, achieve biophysically homogeneous regional units, nor pass through areas of minimum community interest.

Application of the eco-civic methodology to design local to regional frameworks and institutions for resource governance could also be useful in the review of local government areas and regional planning. For example, level three eco-civic regions would be appropriate for resource governance at the current scale of local government. These nest into level two regions appropriate for regional planning, to replace catchment management areas or national action plan areas for natural resources management, and for state and federal coordination of regional service delivery. Eco-civic level one regions could be useful for resource governance issues that have externalities going beyond levels one and two. 
Of course, there will be externalities that reach beyond the borders of New South Wales that will require even larger regions; however, a national application of the methodology is required to delineate their boundaries.

\section{Acknowledgements}

The NSW Department of Lands and the Commonwealth funding body, Land and Water Australia, have supported different elements of this research. Our conclusions do not necessarily reflect the policies of these organisations. We greatly appreciated assistance in data analysis, GIS and mapping, and review from Karl Bock, Phil Morley, Phil Coop, Judith McNeill, Annemieke van der Meulen, Brendan Doyle, Graham Marshall and Richard Stayner.

\section{References}

Altman, I. and Low, S.M. (eds) 1992. Place attachment. Plenum Press, New York.

Austin, D.E. 1994. Incorporating cognitive theory into environmental policymaking. Environmental Professional, 16: 262-74.

Bailey, R.G. 1996. Multi-scale ecosystem analysis. Environmental Monitoring and Assessment, 39: 21-4.

Barham, E. 2001. Ecological boundaries as community boundaries: the politics of watersheds. Society and Natural Resources, 14: 181-91.

Beckley, T.M. 1995. Community stability and the relationship between economic and social well-being in forest-dependent communities. Society and Natural Resources, 83: 261-66.

Berkes, F. and Folke, C. (eds) 1998. Linking social and ecological systems: management practices and social mechanisms for building resilience. Cambridge University Press, Cambridge.

Blomquist, W. and Schlager, E. 2005. Political pitfalls of integrated watershed management. Society and Natural Resources, 18: 101-17.

Brandenburg, A.M. and Carroll, M.S. 1995. Your place, or mine: the effect of place creation on environmental values and landscape meanings. Society and Natural Resources, 8: 381-98.

Brown, J. and MacLeod, N. 1996. Integrating ecology into natural resource management policy. Environmental Management, 203: 289-96.

Brunckhorst, D.J. 2000. Bioregional Planning: Resource Management Beyond the New Millennium. Harwood Academic, Taylor and Francis, Amsterdam.

Brunckhorst, D.J. 2002. Institutions to sustain ecological and social systems. Ecological Management and Restoration, 32: 109-17.

Brunckhorst D.J. and Coop, P. 2001. The influence of social eco-logics in shaping novel resource governance frameworks. In: Lawrence, G., Higgins, V. and Lockie, S. (eds) Environment, society and natural resource management: theoretical perspectives, Edward Elgar Academic Press, UK.
Brunckhorst, D., Coop, P. and Reeve, I. 2006. Eco-civic optimisation: a nested framework for planning and managing landscapes. Landscape and Urban Planning, 75(3-4): 265-281.

Brunckhorst, D., Reeve, I. and Coop, P. 2004. Eco-civic regionalisation for New South Wales. Published report to the New South Wales Government, New South Wales Department of Lands and Institute for Rural Futures, University of New England, Armidale. Online at http://www.ruralfutures.une. edu.au/ downloads/ecocivic_177.pdf (accessed 16 February 2007).

Buchy, M., Ross, H. and Proctor, W. 2000. Enhancing the information base on participatory approaches in Australian natural resource management. In: Land and Water Australia (ed.) Natural Resources Management - People and Policy, Land and Water Australia, Canberra.

Carletta, J. 1996. Assessing agreement on classification tasks: the kappa statistic. Computational Linguistics, 122: 249-54.

Carpenter, S.R. and Gunderson, L.H. 2001. Coping with collapse: ecological and social dynamics in ecosystem management. Bioscience, 516: 451-57.

Carr, A.J. 2004. Why do we all need community science? Society and Natural Resources, 179: 841-49.

Carrothers, G. 1956. A historical review of the gravity and potential concepts of human interaction. Journal of American Institute of Planners, 22: 94-102.

Cheng, A.S., Kruger, L.E. and Daniels, S.E. 2003. Place as an integrating concept in natural resource politics: propositions for a social science research agenda. Society and Natural Resources, 162: 87-104.

Christaller, W. 1933. Central places in Southern Germany, trans. C.W. Baskin 1966. Prentice-Hall, Englewood Cliffs, NJ.

Cole, D.H. 2002. Pollution and property: comparing ownership institutions for environmental protection. Cambridge University Press, Cambridge.

Coop, P. 2003. Eco-civic landscapes: capturing civic interest in multi-scale natural resource management frameworks. $\mathrm{PhD}$ thesis, University of New England, Armidale, NSW.

Cuba, L. and Hummon, D.M. 1993. A place to call home: identification with dwelling, community, and region. Sociology Quarterly, 34: 111-31.

Dollery, B. and Johnson, A. 2005. Enhancing efficiency in Australian local government: and evaluation of alternative models of municipal governance. Urban Policy and Research, 231: 73-85.

Ewing, S. 2003. Catchment management arrangements. In: Dovers, S. and Wild River, S. (eds) Managing Australia's environment, Federation Press, Sydney, pp. 393-412.

Feld, S. and Basso, K.H. 1996. Senses of Place. School of American Research Press, Santa Fe.

Fenton, M., Coakes, S. and Marshall, N. 2000. Social assessment in natural resource management: the development and application of town resource cluster analysis TRCAnalysis. Mimeo.com. 
Field, D.R., Voss, P.R., Kuczenski, T.K., Hammer, R.B. and Radeloff, V.C. 2003. Reaffirming social landscape analysis in landscape ecology: a conceptual framework. Society and Natural Resources, 164: 349-62.

Forman, R.T. 1995. Land mosaics: the ecology of landscapes and regions. Cambridge University Press, Cambridge.

Forman R.T. and Godron, M. 1981. Patches and structural components for landscape ecology. BioScience, 31: 733-40.

Fulcher, H. 1989. The Concept of Community of Interest. Discussion paper 2. South Australian Department of Local Government, Adelaide.

Getches, D. 1998. Some irreverent questions about watershedbased efforts. Chronology and Community, 2: 28-34.

Hansen A.J. and di Castri, F. (eds) 1992. Landscape boundaries: consequences for biotic diversity and ecological flows, Springer-Verlag, New York.

Hillery, G.A. 1955. Definitions of community: areas of agreement. Rural Sociology, 20: 111-24.

Hobbs, B.F., Ludsin, S.A., Knight, R.L., Ryan, P.A., Biberhofer, J. and Ciborowski, J.J. 2002. Fuzzy cognitive mapping as a tool to define management objectives for complex ecosystems. Ecological Applications, 12: 1548-65.

House of Representatives Standing Committee on Economics, Finance and Public Administration. 2003. Rates and Taxes. A Fair Share for Responsible Local Government. Parliament of the Commonwealth of Australia, Canberra.

Hugo, G. P., Smailes, P., Macgregor, C., Fenton, M. and Brunckhorst, D. 2001. Defining social catchments in nonmetropolitan Australia. Bureau of Rural Sciences, Australia.

James, R.F. and Blamey, R.K. 1999. Public Participation in Environmental Decision-Making - Rhetoric to Reality? Paper presented at the 1999 International Symposium on Society and Resource Management, Brisbane, Australia, 7 - 10 July.

Johnson, K., Swanson, F., Herring, M. and Greene, S. 1999. Bioregional assessments: science at the crossroads of management and policy. Island Press, Washington D.C.

Kearney, A.R. and Kaplan, S. 1997. Toward a methodology for the measurement of knowledge structures of ordinary people: the Conceptual Content Cognitive Map. Environmental Behaviour, 29: 579-617.

Kemmis, D. 1990. Community and the Politics of Place. University of Oklahoma Press, Norman.

Knight R.L. and Landres, P.B. (eds) 1998. Stewardship across boundaries. Island Press, Washington D.C.

Lane, M.B., McDonald, G.T. and Morrison, T.H. 2004. Decentralisation and environmental management in Australia: A comment on the prescriptions of the Wentworth Group. Australian Geographical Studies, 421: 103-15.

Maiden, H.E. 1966. The history of local government in New South Wales. Angus and Robertson, Sydney.

Margerum, R.D. 1995. Examining the practice of integrated environmental management: towards a conceptual model. $\mathrm{PhD}$ dissertation, University of Wisconsin-Madison.
Marshall, G.R. 2005. Economics for Collaborative Environmental Management: Renegotiating the Commons. Earthscan, London.

McGinnis, M.D. (ed.) 1999. Polycentric Governance and Development. University of Michigan Press, Ann Arbor.

McGinnis,V.M., Wooley, W. and Gamman, J. 1999. Bioregional conflict resolution: rebuilding community in watershed planning and organizing. Environmental Management, 241: 1-12.

Musgrave, W., Conner, N., Gregory, G., Sinden, J.A., Wright, V. and Burge, B. 1985. Local government amalgamations in rural New South Wales, The Rural Development Centre, University of New England, Armidale.

Muskingum Water Conservancy District. 2002. Frequently asked questions about the Muskingum water conservancy district. Online at http://www.mwcdlakes.com/about.htm (accessed 23 March 2006).

NSW Department of Local Government. 2004. Structural reform of local government in New South Wales. NSW Department of Local Government, Sydney.

Omernik, J.M. 1987. Ecoregions of the conterminous United States Level II. Annals of the Association of American Geographers, 771: 118-25.

Omernik, J.M. 1995. Ecoregions: a spatial framework for environmental management. In: Davis, W. and Simon, T. (eds) Biological assessment and criteria: tools for water resource planning and decision making, Lewis Publishing, Boca Raton, Florida, pp. 49-62.

Omernik, J.M. and Bailey, R.G. 1997. Distinguishing between watersheds and ecoregions. Journal of the American Water Resources Association, 335: 1-15.

O’Neill, K.M. 2005. Can watershed management unite town and country? Society and Natural Resources, 18: 241-53.

Parisi, D., Taquino, M., Grice, S.M. and Gill, D.A. 2003. Promoting environmental democracy using GIS as a means to integrate community into the EPA-BASINS approach. Society and Natural Resources, 163: 205-20.

Parisi, D., Taquino, M., Grice, S.M. and Gill, D.A. 2004. Civic responsibility and the environment: linking local conditions to community environmental activeness, Society and Natural Resources, 172: 97-112.

Pattee, H.H. 1973. Hierarchy theory: the challenge of complex systems. Braziller, New York.

Peacock, A.T. and Wiseman, J. 1961. The Growth of Public Expenditures in the United Kingdom. Princeton University Press, Princeton.

Phelps, A. 2003. Total catchment management in New South Wales: Governance rhetoric and reality. thesis, School of Social Science and Policy, University of New South Wales, Sydney.

Reeve I. 1997. Property and Participation: An Institutional Analysis of Rural Resource Management and Landcare in Australia. In: Lockie, S. and Vanclay, F. (eds), Critical Landcare. Centre for Rural Social Research, Wagga Wagga, NSW. 
Reeve, I. 2003. Principles for the nested governance of water resources. Institute for Rural Futures. Occasional paper 2003/1. Online at http://www.ruralfutures.une.edu.au/publications/ occpapers/occpapers.htm (accessed February 2006).

Reeve, I., Frost, L., Musgrave, W. and Stayner, R. 2002a. Agriculture and natural resource management in the MurrayDarling Basin: a policy history and analysis. Published report to the Murray-Darling Basin Commission. Institute for Rural Futures, University of New England, Armidale and MurrayDarling Basin Commission, Canberra.

Reeve, I., Marshall, G. and Musgrave, W. 2002b. Resource governance and ICM. Published report to the Murray-Darling Basin Commission. Institute for Rural Futures, University of New England, Armidale and Murray-Darling Basin Commission, Canberra.

Reid T.S. and Murphy, D.D. 1995. Providing a regional context for local conservation action: a natural community conservation plan for the southern California coastal sage scrub. BioScience Supplement, 1995: 84-90.

Shannon, M.A. 1998. Understanding social organizations and institutions. In: Naiman, R.J. and Bilby, R.E. (eds) River ecology and management: lessons from the Pacific Coastal ecoregion. Springer Verlag, New York, pp. 529-51.

Slocombe, D.S. 1993. Implementing ecosystem-based management: development of theory, practice and research for planning and managing a region. BioScience, 439: 612-22.

Smailes, P.J. 1987. Making boundaries make sure: some principles for defining small-area rural census districts. In: Conacher, A. (ed.) Readings in Australian Geography. Proceedings of the 21 st Conference of the Institute of Australian Geographers, Perth.

Smailes, P.J. 1999. Community social area identification: a case study of rural South Australia. Report to the Bureau of Rural Sciences. Department of Geographical and Environmental Studies, University of Adelaide.

Stedman, R.C. 2003. Is it really just a social construction? the contribution of the physical environment to sense of place. Society and Natural Resources, 168: 671-86.

Syme, G. J., Butterworth, J.E. and Nancarrow, B.E. 1994. National whole catchment management: a review and analysis of processes. Occasional paper 01/94. Land and Water Resources Research and Development Corporation, Land and Water Australia, Canberra.

Tonts, M. and Atherley, K. 2005. Rural restructuring and the changing geography of competitive sport. Australian Geographer, 362: 125-44.

Tuan, Y.F. 1974. Topophilia: A study of environmental perception, attitudes, and values. Prentice Hall, Englewood Cliffs, NJ.

Urban D.L., O'Neill, R.V. and Shugart, H.H. Jr. 1987. Landscape Ecology: A hierarchical perspective can help scientists understand spatial patterns. BioScience, 37(2): 119127.
Waldo, D. 1984. The administrative state: a study of the political theory of American public administration. Holmes and Meier, New York.

Walmsley, D.J. 1977. Communities of Interest and Local Government Boundaries. Shire and Municipal Record, 70(2): 55-57.

Webler, T. and Tuler, S. 1999. Integrating technical analysis with deliberation in regional watershed management planning: applying the National Research Council approach. Policy Studies, 273: 530-43.

Wiken, E. 1986. Terrestrial ecozones of Canada. Ecological land classification series No. 19. Environment Canada, Ottawa.

Wilkinson, K.P. 2000. The Rural Community in America. Social Ecology Press, Middleton, WI. 